INSTITUT NATIONAL DE LA STATISTIQUE ET DES ETUDES ECONOMIQUES

Série des Documents de Travail du CREST

(Centre de Recherche en Economie et Statistique)

\author{
$n^{\circ}$ 2005-14 \\ The Transmission of Aggregate \\ Supply and Aggregate Demand \\ Shocks in Japan : \\ Has There Been a Structural Change? \\ A. BASTIEN \\ F. BEC 2
}

Les documents de travail ne reflètent pas la position de l'INSEE et n'engagent que leurs auteurs.

Working papers do not reflect the position of INSEE but only the views of the authors.

1 EUREQua, Université de Paris 1.

2 CREST-ENSAE, Malakoff, France. Mail : frederique.bec@ensae.fr 


\title{
The Transmission of Aggregate Supply and Aggregate Demand Shocks in Japan: Has There Been a Structural Change?
}

\author{
ALEXIA BASTIEN* AND FRÉDÉRIQUE BEC** \\ *Eurequa, University of Paris 1, Paris, France. \\ ** CREST-ENSAE, Malakoff, France. \\ email: frederique.bec@ensae.fr
}

This version: June 302005

\begin{abstract}
Despite expansionary fiscal and monetary policies, the Japanese real economy has been stagnating since the bubble bursting in the early nineties. Within a multivariate setup, this paper proposes to test for and date a possible structural shift in the response of Japanese macroeconomic fluctuations to aggregate supply and aggregate demand shocks. The econometric methodology directly derives from Andrews [1993] and Bai, Lumsdaine and Stock [1998] theoretical results. Our empirical study from monthly post-1980 observations reveals i) a significant structural break in December 1991, and ii) a sharp decrease in the influence of demand shocks on Japanese output fluctuations after this date.
\end{abstract}

Résumé: Malgré la mise en œuvre de politiques de relance budgétaires et monétaires, la croissance japonaise semble en panne depuis l'éclatement de la bulle au début des années quatre-vingt-dix. Dans un cadre multivarié, cette étude propose de tester et de dater un éventuel changement structurel dans la réponse des fluctuations macroéconomiques japonaises aux chocs d'offre et de demande globales. A cette fin, les résultats théoriques de Andrews [1993] et Bai, Lumsdaine et Stock [1998] sont exploités. L'étude empirique réalisée sur données mensuelles post-1980 révèle i) un changement structurel significatif en décembre 1991, et ii) une diminution marquée de l'influence des chocs de demande sur les fluctuations du produit japonais après cette date.

Keywords: aggregate supply and demand shocks; vector autoregression; structural break. JEL classification: E32, C32.

Acknowledgments: We would like to thank Mélika Ben Salem, Marine Carrasco, Søren Johansen, Guy Laroque, Anders Rahbek and participants at the "Nonlinearities and Cointegration" EMM workshop (Copenhagen, 2004), the CREST seminar (Paris, 2004), the SNDE 13th Annual Symposium (London, 2005), and at the Nuffield College, University of Oxford seminar (Oxford, 2005) for helpful comments on previous versions of the paper. Frédérique Bec gratefully acknowledges financial support from the EMM-ESF Network scheme 2002-2004. Of course, all errors are ours. 


\section{Introduction}

Despite the easing of both fiscal and monetary policies, the Japanese real economy has been stagnating since the bubble burst in the early nineties.

After the collapse of the so-called "bubble economy" ${ }^{1}$, fiscal deficits expanded drastically the Japanese debt to GDP ratio increasing from $40 \%$ to $120 \%$ between 1990 and 2003 - while the official discount rate fell from 6\% in July 1991 to 0.5\% in September 1995 finally reaching $0 \%$ in April 1999. The underlying series of actions by the both the government and the Bank of Japan hence failed to prompt recovery. This apparent lack of response of the Japanese economy to aggregate demand stimulii suggests that at some point of time, the transmission mechanisms vanished. Yet, most of the recent empirical studies seem to neglect that possibility when trying to evaluate the respective contribution of various supply and demand impulses to Japanese economic fluctuations — see e.g. Kasa and Popper [1997], Kwon [1998], Bayoumi and Morsink [2001], Suzuki [2001] or Miyao [2002]. This may explain why the conclusions regarding the relative contributions of structural innovations to Japanese fluctuations are at best mitigated so far.

To our knowledge, the only paper which explicitly tackles the issue of a possible structural shift is Miyao [2000]. Basically, this author performs a likelihood ratio test assuming that the break date is known. This test statistic is computed for each quarter between 1986 and 1997. The null of no structural break is rejected for some quarters in 1995 and 1996 . However, as stressed by Miyao [2000], many dates are good candidates for a structural shift over the sample he studies (January 1975 - April 1998), as e.g. the second oil crisis in the late 1970s, the end of the monetary tightening by the Bank of Japan in 1991 or the historical record of the yen appreciation with respect to the US dollar in 1995. Hence, the timing of a structural shift can hardly be considered as known. Yet, Bai, Lumsdaine and Stock [1998] show that when the date is unknown and must be estimated, the kind of statistics used by Miyao [2000] has a non standard distribution.

The econometric theory of structural change has been deeply renewed from the seminal works of Andrews [1993] and Andrews and Ploberger [1994] on. Indeed, these contributions have paved the way of structural change testing when the exact break point is unknown, hence allowing to estimate the break time. The multivariate extension by Bai et al. [1998] even allows to compute asymptotically valid confidence intervals for the date of the break. These recent developments in econometric theory make it possible to test for - and date - a break in the propagation mechanism of identified economic impulses within e.g. a VAR framework. To our knowledge, these new econometric tools haven't been used so far to analyze the possible change in the transmission of structural shocks to the Japanese economy.

Therefore, this paper aims at filling this gap by properly testing for and dating a possible break point in the Japanese economic dynamics. To this end, we study a very simple VAR model describing the industrial production index and the inflation rate joint dynamics. This model has already been applied to Japanese data by e.g. Hutchison [1994], Bergman [1996] or Mio [2001],

\footnotetext{
${ }^{1}$ We adopt the terminology of Miyao [2000], which refers to "the strong economic boom of the late 1980s associated with unusually high asset prices".
} 
and seems relevant in order to disentangle aggregate demand and aggregate demand shocks.

The main conclusion of our empirical work is that neglecting an actual structural shift leads to fallacious inference. Indeed, when based on the full sample (January 1980 - December 2003), the results suggest that aggregate demand shocks exert a significant - and even dominant influence on real output short run fluctuations. However, when formally tested, the stability hypothesis is rejected and the Japanese data point to a break in December 1991. The year 1991 witnessed the collapse of the land prices bubble ${ }^{2}$ as well as the highest level the overnight call rate ever reached since 1980 . When examining each sub-sample separately, our results tell a quite different story: in the second sub-sample, the influence of aggregate demand shocks on output fluctuations decreases dramatically ${ }^{3}$.

The paper is organized as follows. Section 1 briefly presents the economic theory justifying the choice of the variables included in the VAR model in order to identify aggregate demand and aggregate supply shocks. The data are presented in Section 2, together with empirical testing of their order of integration which in turn allows to choose the appropriate VAR representation. In Section 3, we develop a Sup test relying on Bai et al. [1998] and specifically devised to test for a structural shift in the transmission mechanisms of a VAR model. Section 4 analyses the dynamic effects of demand and supply disturbances and Section 5 evaluates their relative contribution to Japan's output fluctuations. Section 6 concludes.

\section{Identifying aggregate demand and aggregate supply distur- bances}

Basically, the choice of a VAR model including a measure of real output and the inflation rate follows from the theoretical model developed in Blanchard and Quah [1989]. This is a simple AS/AD model, assuming rational expectations and nominal wage rigidities ${ }^{4}$.

First, let us assume that the production technology characterizing the economy is given by:

$$
Y_{t}=\exp \left(u_{t}\right) N_{t}^{a}, \quad 0<a<1
$$

where $Y_{t}$ denotes the output, $N_{t}$ the labour input and $u_{t}$ the global factor productivity. It then follows that the aggregate supply function in logarithms writes:

$$
y_{t}^{s}=a n_{t}+u_{t},
$$

and $u_{t}$ is assumed to be a random walk process:

$$
u_{t}=u_{t-1}+\varepsilon_{t}^{s}
$$

with $\varepsilon_{t}^{s}$ an i.i.d. supply shock. The labour demand function which maximizes the firms profit is:

$$
n_{t}^{d}=\frac{1}{a-1}\left(w_{t}-p_{t}\right)+\frac{1}{1-a} u_{t}+\frac{1}{1-a} \log (a)
$$

\footnotetext{
${ }^{2}$ The asset price bubble collapsed one year before, in 1990 .

${ }^{3}$ This result supports the findings by Miyao [2000].

${ }^{4}$ See also Bergman [1996].
} 
where $w_{t}$ and $p_{t}$ denote the logarithms of the nominal wage and the price level respectively. Regarding aggregate demand, we will retain its simplest version:

$$
y_{t}^{d}=v_{t}-p_{t}
$$

where the stochastic demand disturbance $v_{t}$, including e.g. money stock and public spending, is also assumed to be a random walk:

$$
v_{t}=v_{t-1}+\varepsilon_{t}^{d}
$$

Here again, the aggregate demand shock $\varepsilon_{t}^{d}$ is an i.i.d. process, uncorrelated with $\varepsilon_{t}^{s}$.

The price $p_{t}$ is perfectly flexible and hence adjusts the good market equilibrium at each date, which yields from (2) and (5):

$$
p_{t}=v_{t}-u_{t}-a n_{t}
$$

Nominal wage rigidities are introduced through contracts $\grave{a} l a$ Fischer [1977]. Indeed, the nominal wage for time $t$ is chosen one period in advance so as to achieve expected full employment at time $t$. Assuming a constant labour supply at level $\bar{n}$ for all $t, w_{t}$ is set at time $t-1$ such that:

$$
E_{t-1}\left(n_{t}^{d}\right)=\bar{n}
$$

where $E_{t-1}($.$) denotes the rational expectation conditional to the information set available in t-1$. Using (8) together with (4) and (7), the resulting nominal wage is given by:

$$
w_{t}=\log (a)-\bar{n}+v_{t-1}
$$

From this predetermined value of $w_{t}$, the equilibrium price $p_{t}$ is then straightforwardly obtained from equations (4) and (7), which in turn allows to characterize the solution in $y_{t}$. As a result, the model's predictions regarding the output and the inflation rate dynamics are:

$$
y_{t}=a \bar{n}+a \varepsilon_{t}^{d}+u_{t}
$$

and

$$
\Delta p_{t}=(1-a) \varepsilon_{t}^{d}-\varepsilon_{t}^{s}+a \varepsilon_{t-1}^{d}
$$

Hence, due to nominal wage rigidities, demand disturbances have transitory effects on output. However, only supply shocks affect this variable in the long-run. Since the supply shocks affect $y_{t}$ permanently, through $u_{t}$ in equation (10), the output process should be integrated of order one. As can be seen from equation (11), none of the disturbances have a long-run effect on the inflation rate, which should hence be a stationary variable.

Accordingly, the analysis of a bi-variate VAR model including the output and the inflation rate should be relevant to identify aggregate supply and aggregate demand shocks ${ }^{5}$, by imposing the identifying restriction that the supply disturbances are the only ones which affect the output in the long run.

\footnotetext{
${ }^{5}$ See Blanchard and Quah [1989] for further discussion on that point.
} 


\section{The vector autoregression setup}

The vector autoregression retained in the sequel includes the logarithm of industrial production index $(y)$ and the year on year change in the consumer price index ${ }^{6}(\pi)$. These monthly data come from Datastream and are seasonally adjusted. We use monthly observations from 1980:01 to $2003: 12 .^{7}$

We begin the empirical analysis by checking the order of integration of the data. To this end, we perform the ADF-GLS unit root test proposed by Elliott, Rothenberg and Stock [1996] as well as the stationarity KPSS test by Kwiatkowski, Phillips, Schmidt and Shin [1992]. The results are reported in Table 1 . The tests for the variables in levels include a constant and a linear deterministic trend, whereas the tests for the variables in first differences include a constant term only. Both the ADF-GLS and KPSS statistics lead to conclude that $y$ is integrated of order one

Table 1: I(1)/I(0) tests

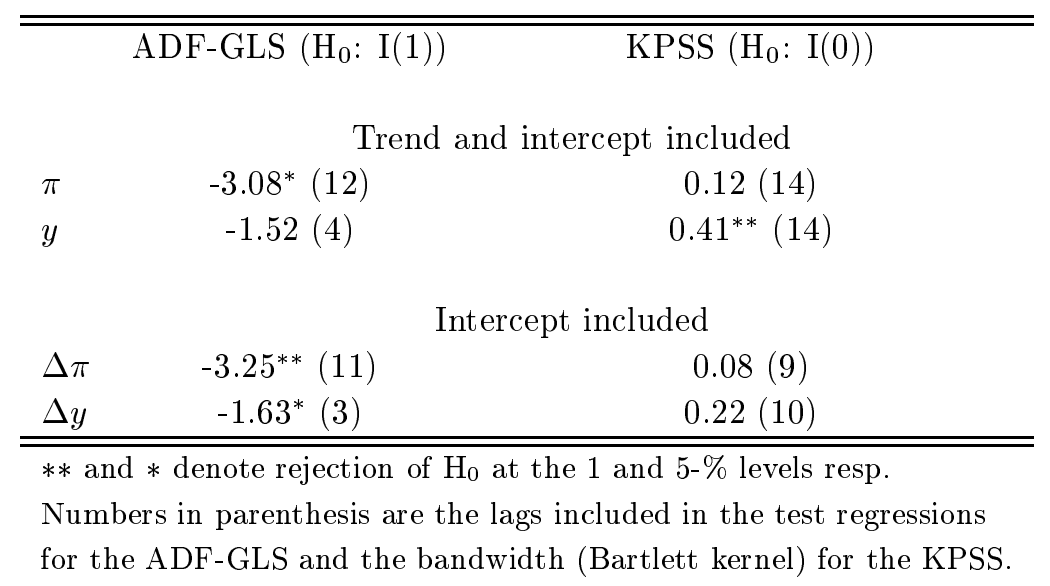

whereas the inflation rate is trend stationary. This conclusion is also supported by the Johansen [1996]'s trace test of cointegration ${ }^{8}$. Performing the test including an unrestricted constant and a trend in the cointegration space ${ }^{9}$, the test statistics strongly rejects the null of no cointegration with a value of 34.87 , while the null of at most one cointegration relation is not rejected at the $5 \%$ level, with a statistics value of 12.37 . Moreover, the likelihood ratio test that $y$ can be excluded

\footnotetext{
${ }^{6}$ It is calculated as $\frac{c p i(t)-c p i(t-12)}{c p i(t-12)} \times 100$. Following Miyao [2000], the logarithm of industrial production index is also multiplied by 100 .

${ }^{7}$ Even though earlier data are available, we deliberately choose to start in 1980:01 in order to avoid possible structural breaks in the 1970s such as the two oil crisis. Indeed, the econometric theory developed in Bai et al. [1998] applies for single break only.

${ }^{8}$ Recently, Johansen, Mosconi and Nielsen [2000] and Lütkepohl, Saikkonen and Trenkler [2004] have extended the cointegration rank test to allow for a shift in the deterministic trend at known break points in the former, and a shift in the mean at unknown date in the latter. To our knowledge, the case of a general structural change considered next section below has not been analysed so far.

${ }^{9}$ See Johansen [1996], Table 15.4. The lag order of the VAR in levels is set to 14 according to the AIC criterium.
} 
from the cointegration relation does not reject the null at the 5\%-level.

However, it is now well-known that if the log output is actually stationary around a deterministic time trend which has one slope in an initial fraction of the sample and, later, a different slope, then the conventional unit-root test statistics will incorrectly fail to reject the unit-root null. Therefore, we also perform the tests developed by Banerjee, Lumsdaine and Stock [1992] which specifically aim at testing the unit-root against the alternative of stationarity around broken trend lines, the break dates being treated as unknown a priori ${ }^{10}$. The recursive, rolling and sequential statistics are gathered in Table 2. Following Banerjee et al. [1992], the recursive statistics are computed using subsamples $t=1, \ldots, k$ for $k=k_{0}, \ldots, T$ where the start-up value $k_{0}$ is located at $\frac{T}{4}$; the rolling statistics are computed from subsamples whose size is $\frac{T}{3}$, rolling through the sample; the sequential statistics are computed using the full sample, sequentially incrementing the date of the possible shift between $0.15 T$ and $0.85 T$. Even though allowing for a trend or

Table 2: BLS unit-root tests

\begin{tabular}{|c|c|c|c|c|c|c|c|c|c|}
\hline \multirow[b]{2}{*}{ statistics } & \multicolumn{2}{|c|}{ Recursive } & \multicolumn{2}{|c|}{ Rolling } & \multicolumn{5}{|c|}{$\overline{\text { Sequential }}$} \\
\hline & $\hat{t}_{D F}^{\max }$ & $\hat{t}_{D F}^{\min }$ & $\bar{t}_{D F}^{\max }$ & $\bar{t}_{D F}^{m i n}$ & $\begin{array}{r}\text { trend } \\
\tilde{t}_{D F}(\tilde{\delta})\end{array}$ & $\begin{array}{l}\text { hift } \\
\tilde{t}_{D F}^{\min } \\
\end{array}$ & $\begin{array}{r}\text { mear } \\
\tilde{t}_{D F}(\tilde{\delta}) \\
\end{array}$ & $\begin{array}{l}\text { shift } \\
\tilde{t}_{D F}^{m i n} \\
\end{array}$ & $\begin{array}{l}\text { restricted } \\
\operatorname{ext}_{\delta} \tilde{t}_{\tau 1}(\tilde{\delta})\end{array}$ \\
\hline break date $(=\tilde{\delta} T)$ & & & & & $90: 04$ & & $87: 06$ & & $90: 11$ \\
\hline & -0.25 & -2.69 & 0.22 & -3.47 & -4.18 & -4.18 & -3.52 & -3.52 & -1.86 \\
\hline $5 \%$ critical values & -1.94 & -4.18 & -1.48 & -4.85 & -4.39 & -4.39 & -4.79 & -4.80 & -2.92 \\
\hline
\end{tabular}

All the statistics where computed with 4 lags, according to AIC. The critical values come from Tables 1 and 2 in Banerjee et al. [1992], for $T=250$.

mean shift under the stationary alternative, these tests fail to reject the unit-root null at the $5 \%$ level. Moreover, when imposing the unit-root and testing for a shift in the mean growth rate (last column of Table 2), the null of a constant drift is not rejected by the data. Finally, we also test for a trend or a mean shift in the inflation rate. Since this series has been found stationary, the Sup-tests proposed by Andrews [1993] — treating the break date as unknown - can be used. The SupLR statistics obtained for the test of a shift in the trend (i.e. change in slope) is 5.721, and the bootstrapped $p$-value is 0.67 , hence failing to reject the stability of the trend slope. When testing for a mean shift (i.e. jump in the trend), the SupLR equals 7.99 with a bootstrapped $p$-value of 0.45 . Again, the stability null is not rejected ${ }^{11}$.

Hence, the VAR model estimated below includes $\pi$ in levels, $\Delta y$ and both a constant and a time trend in the deterministic component:

$$
X_{t}=\mu_{0}+\delta_{0} t+A(L) X_{t-1}+\tilde{\varepsilon}_{t}
$$

where $X_{t}=\left(\Delta y_{t}, \pi_{t}\right)$. The order of the lag polynomial $A(L)$ is set to 13 , according to the AIC criterium. This is also the smallest lag length succeeding in eliminating residuals autocorrelation.

\footnotetext{
${ }^{10}$ The corresponding Gauss codes were kindly provided by the authors.

${ }^{11}$ These tests were performed with 13 autoregressive lags in levels, following the AIC criterium.
} 


\section{Testing for a structural change}

A VAR model allowing for a general structural change at time $\tau=T \pi$, with $\pi \in(0,1)$, can be written as:

$$
X_{t}=\mu_{0}+\delta_{0} t+A(L) X_{t-1}+D(t>\tau)\left(\mu_{1}+\delta_{1} t+B(L) X_{t-1}\right)+\varepsilon_{t},
$$

where $\mu_{i}, \delta_{i}(i=0,1), X_{t}$, and $\varepsilon_{t}$ are $n \times 1$ with $E\left(\varepsilon_{t} \varepsilon_{t}^{\prime}\right)=\Sigma$. $A(L)$ and $B(L)$ are lag polynomials of known order $p$ such that the roots of $(I-A(L) L)$ and of $(I-A(L) L-B(L) L)$ are outside the unit circle. $D(t>\tau)$ is a dummy variable such that $D(t>\tau)=0$ for $t \leq \tau$ and $D(t>\tau)=1$ for $t>\tau$.

Under the null hypothesis that no break occurs, model (12) rewrites:

$$
X_{t}=\mu_{0}+\delta_{0} t+A(L) X_{t-1}+\tilde{\varepsilon}_{t}
$$

with $E\left(\tilde{\varepsilon}_{t} \tilde{\varepsilon}_{t}^{\prime}\right)=\Sigma_{c}$. Hence, the null hypothesis of no structural break at time $\tau$ corresponds to:

$$
H_{0}: \mu_{1}=0, \delta_{1}=0 \text { and } B=0
$$

where $B$ is a vector whose elements are the $b_{i j}^{k}$ parameters of $B(L), i=1, \ldots, n, j=1, \ldots, n$ and $k=1, \ldots, p$. If the break point $\tau$ were known, then standard likelihood ratio (LR), Lagrange Multiplier (LM) or Wald (W) test statistics could be used to test $H_{0}$. If $\tau$ is unknown, the difficulty is that there is no estimate of $\tau$ under the null hypothesis: $\tau$ is a nuisance parameter under the null. The parameters $\mu_{1}, \delta_{1}$ and $B$ are also unidentified nuisance parameters under $H_{0}$. With $\tau$ unknown, we will follow the common practice initiated by Davies [1987] which consists in using sup tests of the type:

$$
\operatorname{SupLR}(\tau)=\sup _{\tau \in\left[\tau_{\text {inf }}, \tau_{\text {sup }}\right]} L R_{T}(\tau)
$$

where $\tau_{\text {inf }}$ corresponds to the initial fraction of the full sample $T$ which is trimmed, in practice often set to $0.15 T$ as suggested by Andrews [1993] and $\tau_{\text {sup }}=\left(1-\tau_{\text {inf }}\right) T$. Moreover,

$$
L R_{T}(\tau)=\left(T-n_{c}\right)\left(\log \operatorname{det}\left(\Sigma_{c}\right)-\log \operatorname{det}(\Sigma(\tau))\right)
$$

where $n_{c}$ denotes the number of constrained coefficients involved by assumption (14). Note that the LR statistics depends on $\tau$ through the estimate of the variance-covariance matrix of residuals under the alternative (12). Equivalently, one could define SupLM and SupW statistics.

In order to give the asymptotic null distribution of $\operatorname{SupLR}(\pi)$, we need the following further assumptions for the $\varepsilon_{t}$ process in (12), where $V_{t}^{\prime}=\left(1, t, X_{t-1}^{\prime}, \ldots, X_{t-p}^{\prime}, D(t>\tau), D(t>\right.$ $\left.\tau) t, D(t>\tau) X_{t-1}^{\prime}, \ldots, D(t>\tau) X_{t-p}^{\prime}\right)$.

Assumption 1: Let $\varepsilon_{t}$ be a martingale difference sequence with respect to $\mathcal{F}_{t-1}=\sigma$-field $\left(V_{t}, \varepsilon_{t-1}\right.$, $\left.V_{t-1}, \varepsilon_{t-2}, \ldots\right)$ satisfying, for some $\alpha>0, \max _{i} \sup _{t} E\left(\varepsilon_{i t}^{4+\alpha}<\infty\right.$ and $E\left(\varepsilon_{t} \varepsilon_{t-j}^{\prime} \mid \mathcal{F}_{t-1}\right)=\Sigma$ for $j=0$ and 0 otherwise. 
Theorem 1 Under Assumption 1, and given any set $\Pi$ whose closure lies in $(0,1)$, the following processes indexed by $\pi \in \Pi$ satisfy:

i) $L R_{T} \stackrel{L}{\rightarrow} L R^{*}$, where $L R^{*}(\pi)=\|W(\pi)-\pi W(1)\|^{2} /[\pi(1-\pi)]$ and $W($.$) is a vector of independent$ standard Brownian motion processes with $\operatorname{dim}(W)=n_{c}$.

ii) $\operatorname{SupLR}(\pi) \stackrel{L}{\rightarrow} \sup _{\pi \in \Pi} L R^{*}(\pi)$.

Proof of Theorem 1 follows immediately from Andrews [1993] and Bai et al. [1998].

Since the asymptotic null distribution of $\operatorname{Sup} L R(\pi)$ is free of nuisance parameter, the critical values for the test statistics can be tabulated. However, as the empirical use of it will involve a finite number of observations, we will rather use a residual bootstrap method calculated by simulation $^{12}$. For given initial conditions, random draws are made from the residual vectors under the null. From these bootstrap residuals, one can create a simulated sample of series using model (13), and for each sample, calculate the corresponding SupLR statistic. The bootstrap $p$-value then obtains as the percentage of simulated statistics which exceed the actual statistics.

Finally, the maximum likelihood estimator of the break point is given by:

$$
\hat{\tau}=\operatorname{argmax}_{1 \leq \tau \leq T} \mathcal{L}(\tau, \hat{\beta}(\tau), \hat{\Sigma}(\tau))
$$

where $\mathcal{L}($.$) denotes the likelihood function, \hat{\beta}(\tau)$ and $\hat{\Sigma}(\tau)$ denote the estimators of $\operatorname{Vec}\left(\mu_{0}, \delta_{0}, A\right.$, $\left.\mu_{1}, \delta_{1}, B\right)$ and $\Sigma$ which maximize the likelihood function for each given $\tau$. The limiting distribution of $\hat{\tau}$ is given in Bai et al. [1998], Theorem 4, p.401. The explicit expression of its limiting density derives from Picard [1985], and provides us with a simple way of computing the confidence interval of $\hat{\tau}$, see equation (2.21) in Bai et al. [1998].

As shown in Bai et al. [1998], it is straightforward to adapt the SupLR statistics above so as to allow only a subset of coefficients to change. Moreover, as stressed by these authors, tests for partial structural changes will have better power than those for full structural change. Yet, distinguishing between a break in the deterministic components assuming $B=0\left(\mathrm{H}_{0}^{d c}\right)$ and a break in the propagation mechanism assuming $\mu_{1}=\delta_{1}=0\left(\mathrm{H}_{0}^{p m}\right)$ is of particular interest for our empirical analysis. Therefore, the following null hypotheses are also considered:

$$
H_{0}^{d c}: \mu_{1}=\delta_{1}=0
$$

and,

$$
H_{0}^{p m}: B=0
$$

The results of these tests are reported in Table 3, where the bootstrapped p-values are computed from 500 replications.

The test for a full structural change, column $\mathrm{H}_{0}$, rejects the null of stability at the $3 \%$ percent level. However, as can be seen from the last two columns of Table 3, this result comes from a break in the propagation mechanism, since the test for a change in the deterministic components

\footnotetext{
${ }^{12}$ A detailed description of the method can be found in e.g. Hansen [1996] or Hansen and Seo [2002].
} 
Table 3: SupLR tests of a break

\begin{tabular}{cccc}
\hline \hline & $\mathrm{H}_{0}$ & $\mathrm{H}_{0}^{d c}$ & $\mathrm{H}_{0}^{p m}$ \\
\hline SupLR & 93.56 & 13.94 & 89.79 \\
p-value & 0.030 & 0.224 & 0.012 \\
\hline \hline
\end{tabular}

doesn't reject the null of stability - hence confirming the findings from the preliminary univariate analysis. When allowing for a change in the propagation mechanism only, the break point which maximizes the likelihood function, $\hat{\tau}$, is 1991:12. The corresponding $5 \%$ confidence interval is [1990:10,1993:02]. This year coincides with the collapse of the bubble on land prices, and is the year following the burst of asset prices bubble. Yet, as stressed by Kwon [1998], a large fraction of Japanese business investment is financed by intermediated loans which require collateral, and about $45 \%$ of total secured bank loans have been collaterized by land, compared to roughly $3 \%$ by stocks and bonds. Hence, the burst of the land prices bubble is a likely break date.

\section{Dynamic effects of demand and supply disturbances}

The impulse response functions of output and inflation estimated from the full sample are reported in Figure 1. The ones corresponding to the two sub-samples are presented in 2 and 3. As regards the sub-samples, we performed the analysis both maintaining the 13 lags as in the full sample, and choosing the minimum lag order which succeeds in eliminating residuals auto-correlation - it leads to retain 5 lags for the first period and 6 lags for the second one. The results reported below correspond to the latter approach, but all the conclusions remain unchanged with 13 lags. These figures plot the responses to a unit shock, together with their two-standard error band obtained from 500 bootstrapped simulations. They are consistent with a traditional view of the dynamic effects of demand and supply shocks, according to which i) aggregate demand disturbances have a positive short-run impact on both output and inflation and ii) aggregate supply disturbances increase the output and decrease the inflation rate. These results support the relevance of the identifying long-run restriction. According to the latter, the demand shocks have only a transitory impact on the output: their effect on output vanishes after two years. These qualitative results are similar across sub-samples, as can be seen from Figures 2 and 3.

\section{Relative contributions of demand and supply disturbances}

Having checked the relevance of the innovations identification scheme from the impulse response functions, the next step is to assess their relative contribution to output and inflation fluctuations. This can be done formally by computing variance decompositions of output and inflation at various horizons. The forecast error variance decompositions related to the full sample and the two sub-samples are reported in Table 4. When looking at the first two columns, reporting the 

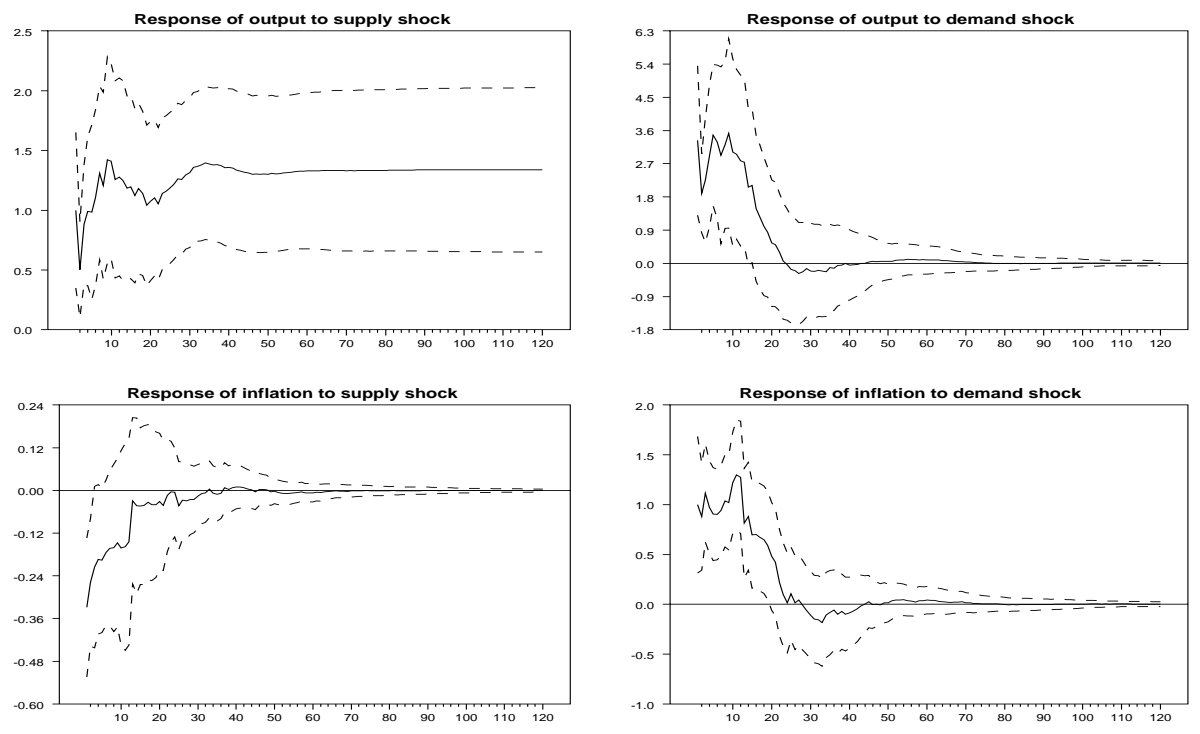

Figure 1: Japan: 1980M1 - 2003M12
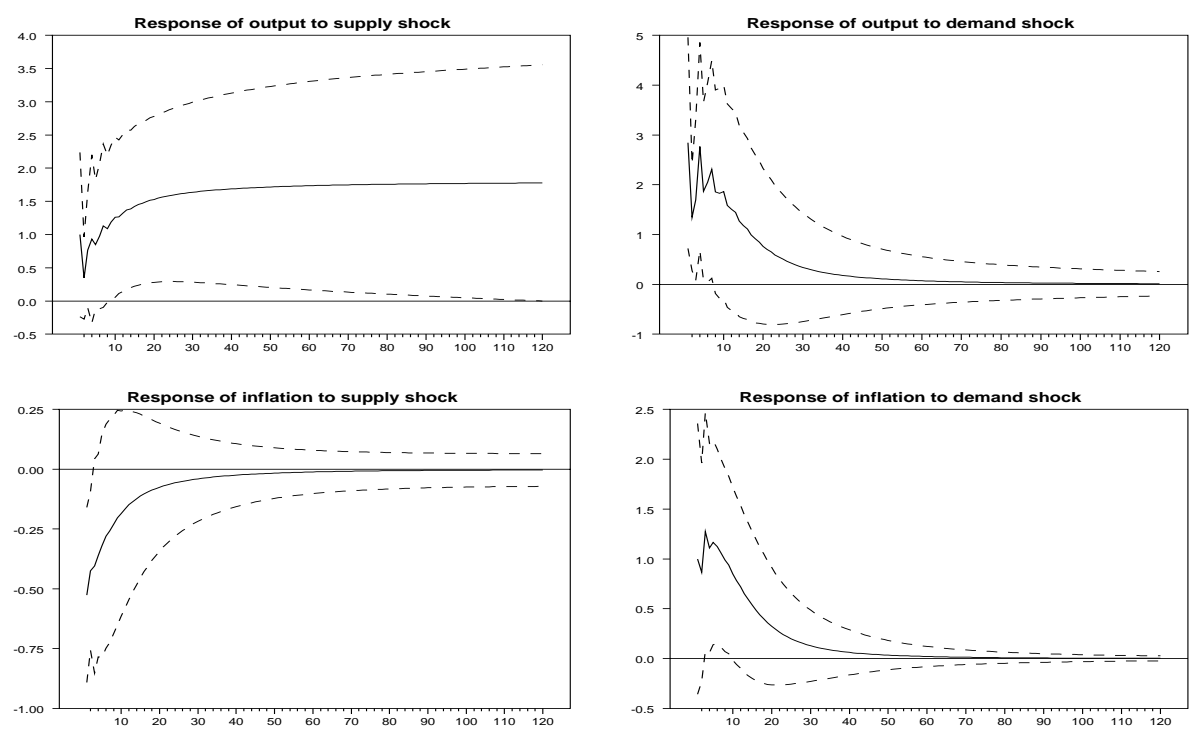

Figure 2: Japan: 1980M1 - 1991M12 
Table 4: Forecast Error Variance Decomposition

\begin{tabular}{l|cccccc}
\hline \hline & \multicolumn{6}{|c}{ Decomposition of output } \\
& \multicolumn{7}{|c}{ horizon } & $1980: 01-2003: 12$ & $1980: 01$ & $1991: 12$ & $1992: 01$ & $-2003: 12$ \\
1 & $\varepsilon^{s}$ & $\varepsilon^{d}$ & $\varepsilon^{s}$ & $\varepsilon^{d}$ & $\varepsilon^{s}$ & $\varepsilon^{d}$ \\
3 & 40.54 & 59.46 & 26.94 & 73.06 & 51.79 & 48.21 \\
6 & 43.69 & 56.31 & 29.00 & 71.00 & 54.16 & 45.84 \\
12 & 43.48 & 56.52 & 27.11 & 72.89 & 56.13 & 43.87 \\
24 & 51.78 & 48.22 & 35.11 & 64.89 & 67.50 & 32.50 \\
36 & 63.05 & 36.95 & 60.17 & 39.83 & 83.35 & 16.65 \\
60 & 74.29 & 25.71 & 75.87 & 24.13 & 89.33 & 10.67 \\
120 & 84.66 & 15.34 & 88.31 & 11.69 & 93.66 & 6.34 \\
& 92.37 & 7.63 & 95.31 & 4.69 & 96.85 & 3.15 \\
& \multicolumn{7}{|c}{ Decomposition of inflation } & \\
horizon & $1980: 01-2003: 12$ & $1980: 01$ & $-1991: 12$ & $1992: 01-2003: 12$ \\
1 & $\varepsilon^{s}$ & $\varepsilon^{d}$ & $\varepsilon^{s}$ & $\varepsilon^{d}$ & $\varepsilon^{s}$ & $\varepsilon^{d}$ \\
3 & 63.04 & 36.96 & 79.40 & 20.60 & 52.25 & 47.75 \\
6 & 53.19 & 46.81 & 66.96 & 33.04 & 54.21 & 45.79 \\
12 & 47.54 & 52.46 & 62.03 & 37.97 & 48.22 & 51.78 \\
24 & 35.71 & 64.29 & 59.43 & 40.57 & 36.80 & 63.20 \\
36 & 29.60 & 70.40 & 58.86 & 41.14 & 33.39 & 66.61 \\
60 & 29.94 & 70.06 & 58.77 & 41.23 & 33.45 & 66.55 \\
120 & 29.94 & 70.06 & 58.75 & 41.25 & 33.44 & 66.56 \\
\hline \hline
\end{tabular}



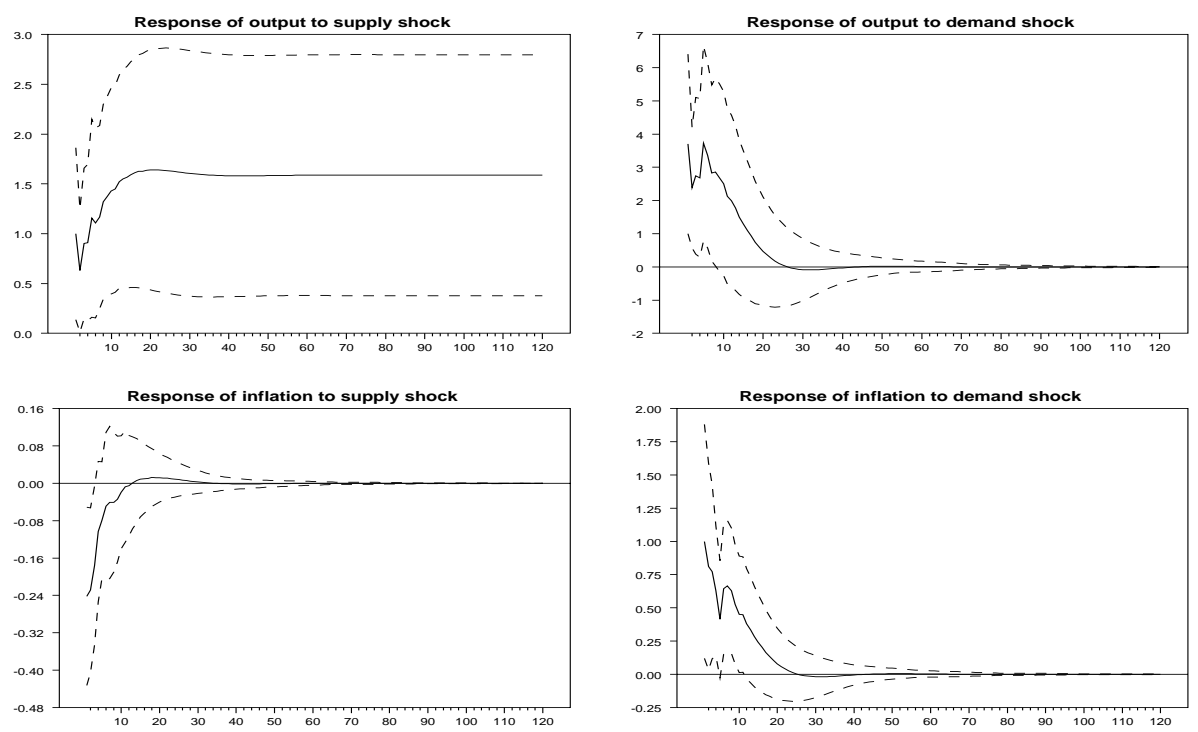

Figure 3: Japan: 1992M1 - 2003M12

decomposition obtained from the full sample VAR estimation, it appears that by neglecting the structural break, one would conclude to the dominance of aggregate demand innovations in the short-run Japanese output fluctuations. However, when looking at sub-sample results, it appears that the contribution of demand shocks to the variance of output is roughly divided by two in the second sub-sample compared to the first one. Actually, at business cycle horizons, demand disturbances dominate the output variance according to the first sub-sample. For instance, their contribution reaches still $64.9 \%$ after one year, whereas by contrast, the second sub-sample analogue is only $32.5 \%$. Hence, these results support the view that the effects of aggregate demand shocks on the Japanese output fluctuations have sharply decreased over the last decade.

Next, when considering the decomposition of the variance of the inflation rate - bottom part of Table 4 - it turns out that the contribution of demand disturbances increases over the second sub-sample. Whereas the inflation rate variance is always dominated by supply shocks during the eighties, it is dominated by demand shocks for all horizons greater than three months during the nineties.

The relative contributions of demand and supply disturbances to the output fluctuations can also be assessed from an historical decomposition analysis. Figures 4 and 5 report for the two sub-samples the output predicted by the model when setting demand shocks to zero (top panel) and the demand component of output fluctuations calculated as the actual output minus the previous series - i.e. the output fluctuations absent demand - (bottom panel). The shaded areas correspond to the recession periods dated by the Economic and Social Research Institute (ESRI) of the Government of Japan. Each shaded area begins with a peak and ends with a trough. As can be seen from Figure 4, the peaks and troughs of the demand component match closely the 

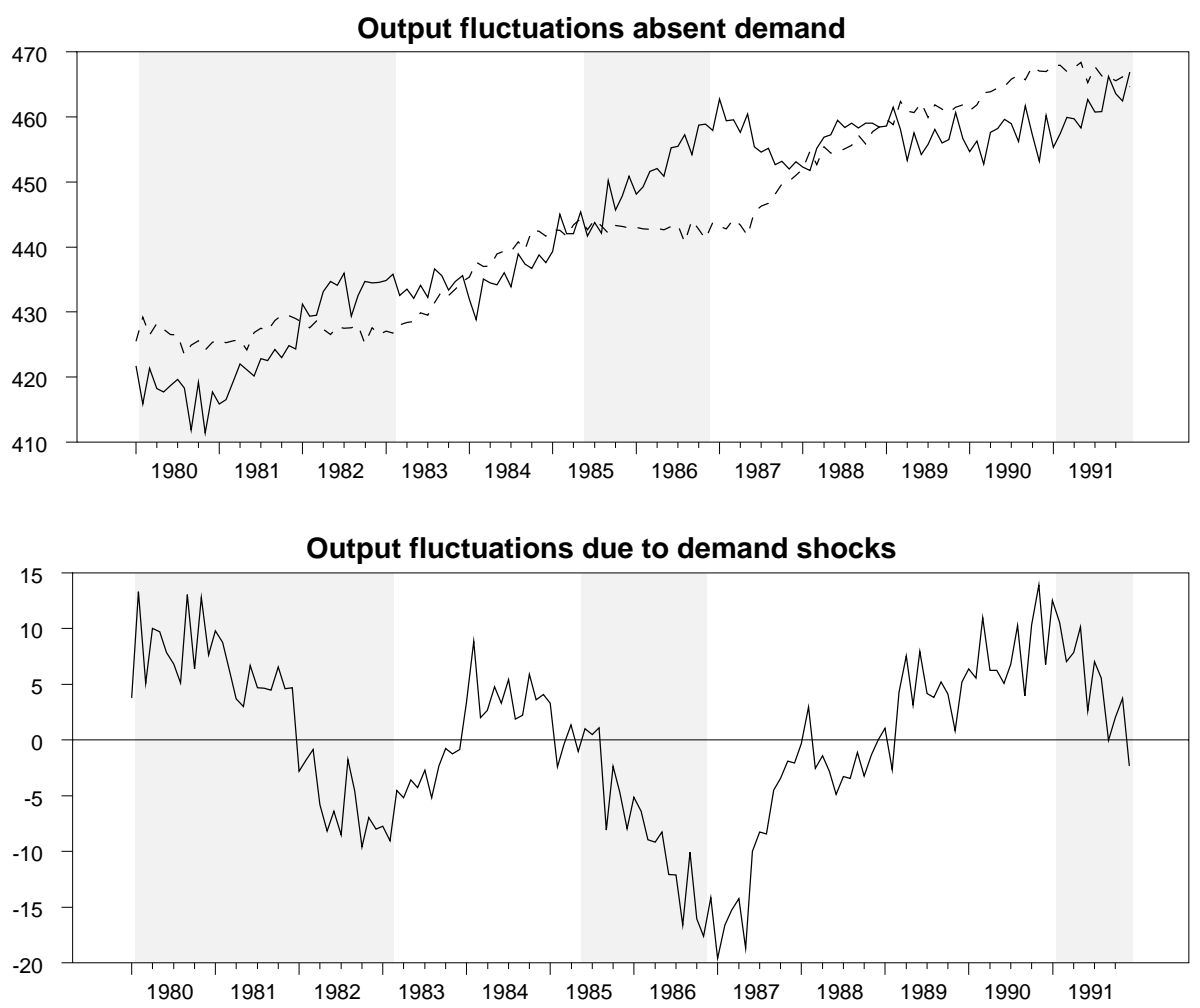

Figure 4: Japan: 1980M1 - 1991M12 
ESRI business cycles datation. This is particularly obvious for the 1980-1983 recession, for the trough in November 1986 and for the peak in February 1991. This support Miyao [2002] conclusion that the burst of Japan's "bubble economy" was caused by demand contraction. Indeed, this may partly be explained by the last series of monetary policy tightening measures implemented by the Bank of Japan in 1989-1991. By contrast, the peak detected in 1985 is entirely due to the supply component. Hence, these results confirm the role of demand disturbances in explaining output fluctuations over this sample. When examining the same historical decomposition over the second sub-sample (Figure 5), the link between the peaks and troughs of the demand component and of the ESRI business cycles datation is quite loose. The most striking discrepancy across sub-samples
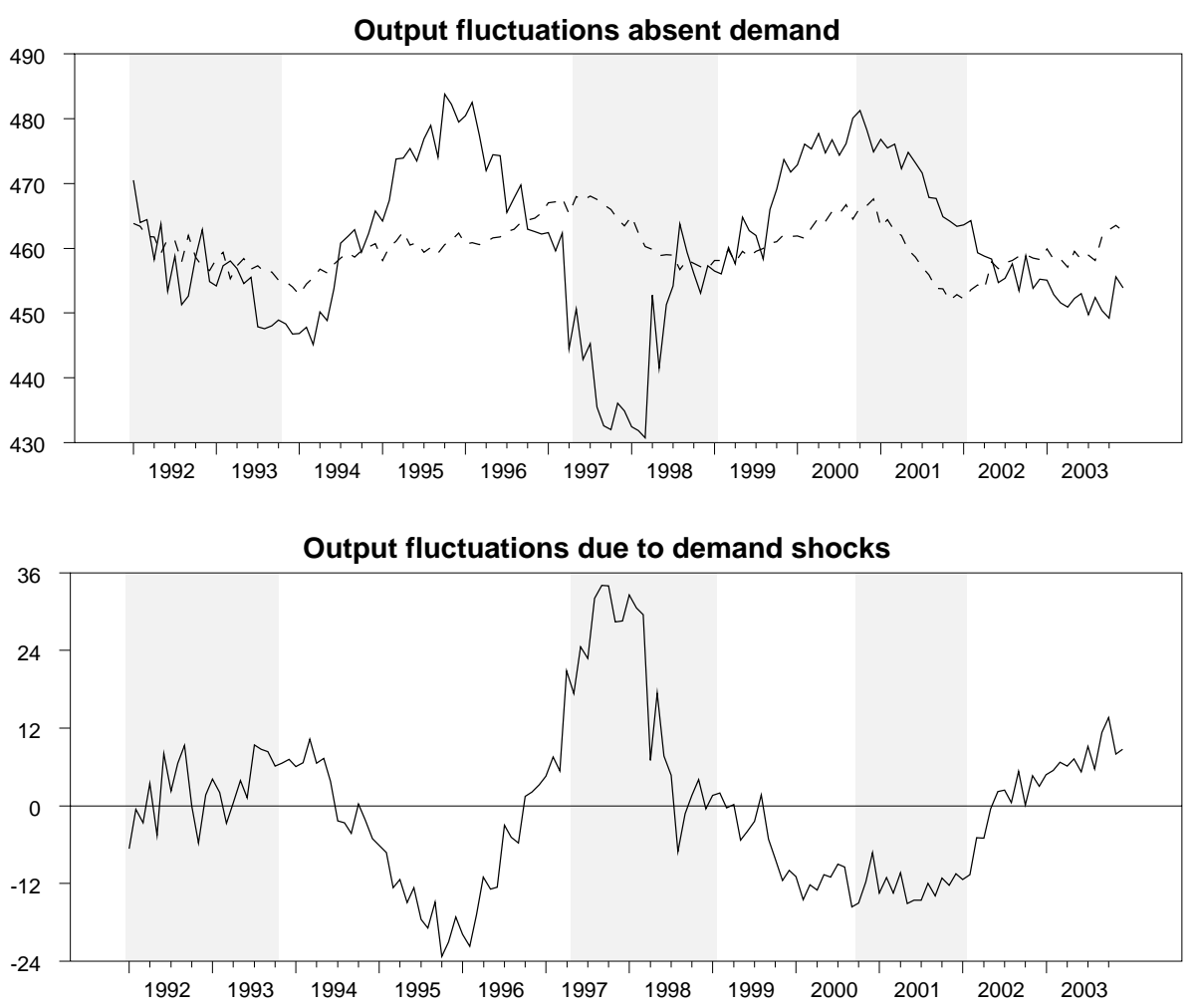

Figure 5: Japan: 1992M1 - 2003M12

is the shape of the demand component of output fluctuations. If demand disturbances were actually causing business cycles, then this component should be downward sloping in recession times (shaded area) and upward sloping otherwise. Basically, this is the case over the first subsample, except for the mid-1984 mid-1985 episode. By contrast, this phenomenon is hardly observed during the nineties apart from the last two recessions where the demand component actually decreases. From that viewpoint, the output fluctuations observed during years 19921996 and 1999-2002 (i.e. roughly eight years out of twelve) would have been mainly leaded by supply disturbances. This finding supports the recent studies by e.g. Hayashi and Prescott 
[2002] and Fukao and Kwon [2004]. Based on aggregate data, Hayashi and Prescott [2002] find that the Total Factor Productivity (TFP hereafter) growth rate fell from $2.4 \%$ during the 19831991 period to an average of $0.2 \%$ for $1991-2000 .{ }^{13}$ The results obtained by Fukao and Kwon [2004] from sectoral data for manufacturing (1994-2001) also confirm our interpretation of supply disturbances. The upward sloping contribution of supply shocks from March 1994 to March 1996 which can be seen from the top panel of Figure 5 corresponds to the positive TFP growth rates calculated by these authors for these two years. Then, the decline in the supply component which we find from March 1996 to March 1998 matches very precisely the negative TFP growth rates in manufacturing found by these authors. For the next two fiscal years, Fukao and Kwon [2004] find a positive TFP growth, again supporting the upward sloping shape of our historical decomposition. Finally, they obtain a negative TFP growth over the last year of their sample (March 2000- March 2001), which is also the year where we find the last turning-point in the supply shocks contribution.

Once again, the conclusions that one would have drawn from the full sample analysis would have been misleading. The corresponding historical decomposition - reported in Figure 6 (see Appendix) - shows that on the whole, the shape of the demand component of output fluctuations is consistent with the view that demand disturbances are an important contributor to economic fluctuations.

\section{Concluding remarks}

The main contribution of our paper is to test for - and date - a structural shift in the propagation mechanisms of aggregate demand and aggregate supply disturbances. To our knowledge, this issue had not been tackled formally so far.

Our findings clearly stress the relevance of such an approach. First, the SupLR test strongly rejects the null of stability in the propagation mechanisms over the 1980:01-2003:12 sample. Second, the break point is located in 1991, which makes sense according to the common belief that since the burst of the Japanese "bubble economy", traditional stabilization policies haven't worked anymore. Finally, when taking this break into account, the results point to a sharp weakening in the aggregate demand disturbances contribution to output fluctuations. The corresponding strengthening of aggregate supply disturbances is consistent with recent studies focusing on the TFP slowdown over the last decade.

More importantly, this conclusion could not have been drawn from a full sample analysis. Hence, we think that such an approach should also be used when trying to evaluate the effects of monetary policy shocks, a topic widely explored recently in order to understand the failure of the Bank of Japan's easing policy to prompt recovery in the nineties. The large majority of existing empirical studies typically rely on a full-sample analysis, including the eighties, and sometimes even the seventies. Consequently, one may suspect that the inference therein is largely

\footnotetext{
${ }^{13}$ Taking the fluctuations of the capacity utilization rate into account, Fukao, Inui, Kawai and Miyagawa [2003] still find a decline in TFP growth rate from period 1983-1991 to period 1991-1998, but only by 0.20 percentagepoints.
} 
contaminated by, say, the first half of the sample, and hence does not apply to current economic conditions. We believe that further work is needed to check this conjecture. 


\section{References}

Andrews, D.W.K., Tests for Parameter Instability and Structural Change with Unknown Change Point, Econometrica, 1993, 61, 821-856.

_ and W. Ploberger, Optimal Tests When A Nuisance Parameter Is Present Only Under The Alternative, Econometrica, 1994, 62 (6), 1383-1414.

Bai, J., R.L. Lumsdaine, and J.H. Stock, Testing For and Dating Common Breaks in Multivariate Time Series, Review of Economic Studies, 1998, 65, 395-432.

Banerjee, A., R. Lumsdaine, and J. Stock, Recursive and Sequential Tests of the Unit-Root and Trend-Break Hypotheses: Theory and International Evidence., Journal of Business and Economic Statistics, 1992, 10 (3), 271-287.

Bayoumi, T. and J. Morsink, A peek inside the black box: The monetary transmission in Japan, IMF Staff Papers, 2001, 48, 22-57.

Bergman, M., International evidence on the sources of macroeconomic fluctuations, European Economic Review, 1996, 40, 1237-1258.

Blanchard, O.J. and D. Quah, The Dynamic Effects of Aggregate Demand and Aggregate Supply Shocks, American Economic Review, 1989, 79 (4), 655-673.

Davies, R. B., Hypothesis Testing When a Nuisance Parameter is Present Only Under the Alternative, Biometrika, 1987, 74, 33-43.

Elliott, G., T. Rothenberg, and J. Stock, Efficient tests for an autoregressive unit root, Econometrica, 1996, 64, 813-836.

Fischer, S., Long-term contracts, rational expectations, and the optimal money supply rule, Journal of Political Economy, 1977, 85, 191-205.

Fukao, K. and H. Kwon, Why Did Japan's TFP Growth Slow Down in the Lost Decade? An Empirical Ananlysis Based on Firm-Level Data of Manufacturing Firms, Hi-Stat Discussion Paper 50, Institute of Economic Research, Hitotsubashi University, Tokyo 2004.

, T. Inui, H. Kawai, and T. Miyagawa, Sectoral Productivity and Economic Growth in Japan, 1970-98: An Empirical Ananlysis Based on the JIP Database, Discussion Paper 67, Economic and Social Research Institute, Tokyo 2003.

Hansen, B. and B. Seo, Testing for Two-Regime Threshold Cointegration in Vector ErrorCorrection Models, Journal of Econometrics, 2002, 110, 293-318.

Hansen, B.E., Inference when a Nuisance Parameter Is Not Identified Under the Null Hypothesis, Econometrica, 1996, 64 (2), 413-430. 
Hayashi, F. and E. Prescott, The 1990s in Japan: A Lost Decade, Review of Economic Dynamics, 2002, 5, 206-235.

Hutchison, M., Asset Price Fluctuations in Japan: What Role for Monetary Policy?, Bank of Japan Monetary and Economic Studies, 1994, 12, 61-83.

Johansen, S., Likelihood-Based Inference in Cointegrated Vector Autoregressive Models, Oxford, UK: Oxford University Press, 1996. 2nd edn.

_ R. Mosconi, and B. Nielsen, Cointegration Ananlysis in the Presence of Structural Breaks in the Deterministic Trend, Econometrics Journal, 2000, 3, 216-249.

Kasa, K. and H. Popper, Monetary policy in Japan : A structural VAR analysis, Journal of the Japanese and International Economies, 1997, 11, 275-295.

Kwiatkowski, D., P.C.B. Phillips, P. Schmidt, and Y. Shin, Testing the null hypothesis of stationarity against the alternative of a unit root. How sure are we that economic time series have a unit root ?, Journal of Econometrics, 1992, 54, 159-178.

Kwon, E., Monetary policy, land prices and collateral effects on economic fluctuations : Evidence from Japan, Journal of the Japanese and International Economies, 1998, 12, 175-203.

Lütkepohl, H., P. Saikkonen, and C. Trenkler, Testing for Cointegration rank of a VAR Process with Level Shift at Unknown Date, Econometrica, 2004, 72, 647-662.

Mio, H., Identifying Aggregate Demand and Aggregate Supply Components of Inflation Rate: A Structural VAR Analysis for Japan, Discussion Paper 2001-E-9, Institute For Monetary and Economic Studies, Bank of Japan 2001.

Miyao, R., The role of monetary policy : A break in the 1990s?, Journal of the Japanese and International Economies, 2000, 14, 366-384.

, The effects of monetary policy in Japan, Journal of Money, Credit and Banking, 2002, 34, 376-392.

Picard, D., Testing and Estimating Change-Points in Time Series, Advances in Applied Probability, 1985, 176, 841-867.

Suzuki, T., The credit channel in Japan : Resolving the supply versus demand puzzle, Working Paper 392, Australian National University 2001. 


\section{Appendix}

\section{A Full sample historical decomposition}
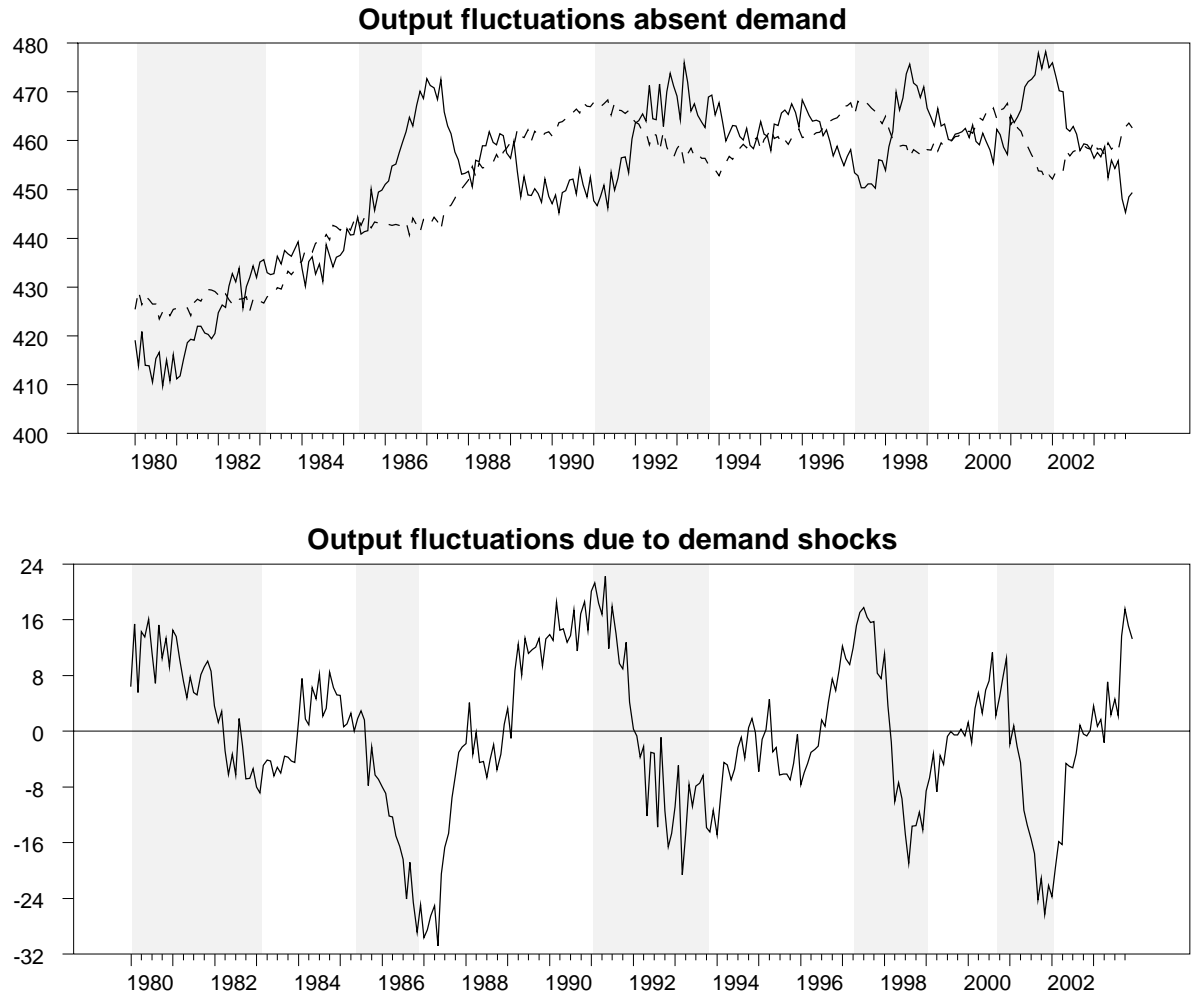

Figure 6: Japan: 1980M1 - 2003M12 